\title{
Equilíbrio espacial de preços com estoque regulador
}

\author{
Janaína Poffo Possamai ${ }^{* *}$, Andresa Pescador ${ }^{\mathrm{b}}$, Sérgio Fernando Mayerle \\ a*janapoffo@gmail.com, FURB, Brasil \\ bandresa.pescador@gmail.com, UDESC,Brasil \\ 'mayerle@deps.ufsc.br, UFSC, Brasil
}

\begin{abstract}
Resumo
Este trabalho apresenta o problema de equilíbrio espacial de preços para produtos sazonais num ambiente de competição perfeita sujeito a estoque regulador sem banda de preços. 0 problema é formulado como um modelo de programação não linear. A solução é obtida com o uso de um algoritmo de projeções, o qual é aplicado a um caso numérico ilustrativo. Os resultados são discutidos e, para fins de comparação, são confrontados com o caso em que não existe o estoque regulador.
\end{abstract}

Palavras-chave

Equilíbrio em redes. Programação não linear. Método do gradiente projetado.

\section{Introdução}

0 comportamento preponderante dos consumidores na aquisição de bens está inteiramente ligado à relação entre as quantidades disponíveis nos mercados e seus preços. Nos períodos em que a oferta de um determinado produto excede muito a procura, seu preço tende a diminuir, e quando a demanda supera a oferta, a tendência é seu preço aumentar. A estabilização da relação entre a oferta e a procura leva, em primeira análise, a uma estabilização do preço.

Ao contrário do que pode parecer, o comportamento da sociedade não é influenciado apenas pelos preços. 0 preço de um produto pode ser um estímulo positivo ou negativo para que os consumidores adquiram os bens que necessitam, mas não é o único. Existem outros elementos a serem considerados nessa equação. Entre eles: os desejos e necessidades das pessoas; o poder de compra; a disponibilidade dos serviços - concorrência; existência de produtos complementares ou substitutos; e outros. A contraposição de todos esses fatores e o preço, por parte de um indivíduo, determina a sua ação em relação à compra. A agregação de todos esses comportamentos permite estabelecer uma função de demanda, decrescente em relação ao preço.

A sazonalidade dos preços de produtos agrícolas, por exemplo, é decorrente da falta de ajustamento entre oferta e demanda dado que a oferta costuma ser concentrada em alguns meses enquanto a demanda é esparsa ao longo do ano. Essa variabilidade de preços ao longo dos meses do ano-safra justifica a adoção de políticas de estoques reguladores, quer por ações públicas, quer por ações privadas ou mistas.

Em virtude da escassez momentânea de certos gêneros, os formadores de preços tendem a pressionar a sua alta. Com a intervenção governamental alimentando o mercado com o produto previamente estocado, tal pressão é minimizada. Os estoques reguladores, sendo eles governamentais, não têm por finalidade obter lucros, apenas objetivam estabilizar os preços praticados, reequilibrando aqueles mercados que estejam sofrendo pressão inflacionária de oferta. A intervenção do governo, em geral, tem o intuito de provocar uma menor desigualdade dos preços agrícolas dentro do ano.

One of the instruments for price stabilization, which is found frequently in the economic literature, is the so-called buffer stock scheme. The basic function of such a program is to store a certain amount of the commodity in boom periods, when the price is low, and to release a certain amount of the stored commodity in bust periods, when the price is high (Athanasiou et al., 2008, p. 1213).

0 problema que envolve estoques reguladores em um modelo econômico de mercado, sendo esse um sistema de concorrência perfeita, é também um 
modelo de equilíbrio. Um sistema está em equilíbrio quando as variáveis de estado não se modificam ao longo do tempo. Em um mercado são as seguintes as variáveis de estado: preços; quantidades produzidas; quantidades transportadas; e quantidades consumidas.

Um dos modelos de equilíbrio de mercado é o de concorrência perfeita em que somente há fluxo entre produtor e consumidor se o custo marginal de produção na origem, acrescido do custo de transporte, for igual ao preço no mercado consumidor. Se for maior não haverá transporte entre esses mercados (Nagurney, 1999).

Neste trabalho estuda-se um modelo de equilíbrio espacial de mercado para produtos sazonais com a interferência de um estoque regulador. A modelagem é descrita por um sistema de concorrência perfeita onde o objetivo é maximizar o excedente da sociedade. Sua resolução é proposta como um problema de programação não linear, o qual é resolvido com o uso de um algoritmo de projeções.

0 artigo é organizado como segue. Na seção 2 apresenta-se a revisão da literatura. Na sequência, seção 3 , faz-se a apresentação do problema em estudo, modelando-o para duas situações: a primeira em que não ocorre armazenagem e a segunda onde considera-se a interferência de estoque regulador. Na seção 4 descreve-se o algoritmo de projeções utilizado. Na seção 5 aplica-se o algoritmo proposto para um caso numérico e os resultados são discutidos. Conclui-se o artigo na seção 6.

\section{Revisão da literatura}

A volatilidade dos preços de commodities agrícolas está diretamente relacionada com as oscilações decorrentes dos períodos de colheita e plantio. No fim do período de colheita tem-se oferta em excesso e os preços tendem a baixar, resultando em perdas para o produtor. Já no período de fim do plantio tem-se escassez na oferta, que influencia o aumento dos preços e consiste em perdas para o consumidor. Assim, equilibrar a oferta e a demanda e consequentemente estabilizar os preços praticados resulta em um ganho para a sociedade.

A maior parte dos trabalhos relacionados com estoques reguladores de commodities tem por objetivo garantir preços mínimos para produtores e/ou preços máximos para consumidores analisando a influência de intervenção pública através do armazenamento ou de controle de importações e a influência de incentivo a estoques privados.

Athanasiou et al. (2008) discutem um modelo que tem por finalidade determinar o custo e o dimensionamento de um estoque regulador proveniente de uma intervenção pública para estabilização de preços de commodities onde avaliam-se os resultados em um comparativo de preços praticados com e sem o armazenamento público. Verifica-se um trade-off entre os custos de armazenamento e a eficiência na estabilização de preços. 0 método utilizado para resolução desse modelo não linear é conhecido por cobweb. Este trabalho foca-se em determinar a quantidade comprada e vendida pelo estoque regulador em cada período, a fim de regularizar os preços, independentemente dos custos de transação para o governo.

Outro modelo é discutido por Brennan (2003), que analisa o impacto dos incentivos de armazenagem no setor privado em relação à intervenção direta do governo no armazenamento, com o intuito de estabilizar os preços do arroz em Bangladesh através do regime de preço máximo. Três modelos são discutidos e comparados através de simulação numérica avaliando-se as variações nos preços praticados. Examinam-se os incentivos para o armazenamento privado, considerando-se uma economia fechada e sem intervenção do governo no mercado; posteriormente, considera-se a intervenção do governo através do armazenamento direto em uma economia fechada e também a intervenção do governo em uma economia aberta onde controla-se a importação. Os modelos discutidos por Brennan são resolvidos através de programação dinâmica e o principal objetivo do trabalho é analisar políticas que mantenham os preços abaixo de um valor máximo, com a preocupação de garantias aos consumidores, sem restrição para os custos de armazenagem.

Sutopo et al. (2008) descrevem um outro modelo, com o intuito de determinar a quantidade a ser estocada pelo governo, a fim de regularizar os preços de mercado considerando a menor perda financeira para produtor, consumidor e estoque governamental. Para tanto, baseiam-se em uma política de preços limite máximos e mínimos. Cobweb é o modelo básico para determinar a quantidade estocada considerando a produção doméstica limitada. Posteriormente resolve-se o modelo considerando-se a função de oferta linear por partes, levando-se em conta restrições que devem ser atendidas pela quantidade armazenada.

Nagurney (1999) apresenta um problema que discute a intervenção política em ambas formulações do modelo de equilíbrio, ora usando a variável quantidade, ora usando o preço. A autora inicia com uma formulação mais simples, considerando $m$ mercados de oferta e $n$ mercados de demanda envolvendo produção e consumo de uma commodity, derivando uma formulação em inequações variacionais para as condições de equilíbrio. Na sequência, a autora generaliza o modelo para multicommodity 
introduzindo custos, preços, fluxos, oferta e demanda para cada commodity. Duas formulações foram realizadas, uma delas para a quantidade, fazendo um controle no preço, e outra para o preço, limitando o fluxo do comércio. Neste trabalho faz-se o uso de um preço fixo mínimo, favorecendo os produtores, e de um preço fixo máximo, tendo-se em conta o consumidor (Nagurney, 1999, p. 115-124).

Edwards \& Hallwood (1980) apresentam uma ilustração abstrata da determinação da quantidade que deve ser armazenada pelos estoques a fim de regularizar os preços através de intervenção pública, utilizando como critério de desempenho o gasto total com armazenagem, que é calculado pela diferença entre preços de venda e de compra, os custo de manutenção dos estoques e o custo da instalação.

Jha \& Srinivasan (2001) avaliam o papel dos estoques reguladores na estabilização dos preços dos grãos na Índia quando o comércio externo está liberado. Discutem o problema numa estrutura de equilíbrio multimercado (arroz e trigo) com comércio endógeno. Examinam a eficácia dos estoques de grãos na estabilização do mercado através de um modelo de simulação dinâmica estocástica multicommodity onde preços, consumo, produção, comércio e estoques são determinados simultaneamente. 0 governo opera com uma política de estabilização de preços mantendo-os dentro de uma faixa de valores e utiliza capacidade limitada para armazenamento físico de grãos.

Prasad et al. (1992) baseiam-se em dois modelos de programação linear integrados e análise de insumo-produto dinâmico na qual incorporam, principalmente, o efeito das chuvas. Fazem uso da análise de sensibilidade para dar conta de caprichos da natureza, em termos de seis diferentes variantes de chuva para a Índia e três para o lrã, a fim de testar se tais resultados ótimos são sensíveis à presença ou ausência de chuvas e restrições de terra.

A preocupação de todos esses modelos é incorporar variáveis e equações/inequações que descrevam da maneira mais real possível a dinâmica dos efeitos da sazonalidade na produção de commodities, analisando através de focos distintos os resultados obtidos, sob a óptica ou do produtor ou do consumidor, agregando modelos de economia aberta e fechada, interferências governamentais e privadas.

A abordagem proposta neste trabalho difere da encontrada na literatura sobre estoques reguladores no sentido de propor um modelo em que se busca a maximização do excedente da sociedade, sem a utilização de limites de banda estabelecidos para os preços praticados em mercados espacialmente distribuídos. Em outras palavras, os preços são livremente determinados por um modelo de competição perfeita, no qual quantidades armazenadas são vendidas no período subsequente, sem que o governo apure lucro ou prejuízo na operação.

Para fins de comparação da estratégia proposta neste trabalho, são apresentadas duas situações: a primeira considera que o consumo ocorre no período de produção; a segunda, que excedentes de produção são armazenados para serem disponibilizados no período seguinte. Para cada uma dessas variantes é apresentada a formulação do modelo de programação matemática, cuja solução é obtida com o uso de um algoritmo de projeções. Um caso numérico ilustrativo é apresentado e os resultados são discutidos. Pode-se dizer que esse trabalho é uma extensão dos trabalhos de Samuelson (1952) e Takayama \& Judge (1971), cujos modelos de equilíbrio espacial de preços são considerados a estrutura básica para uma variedade de aplicações que tratam de equilíbrio de mercados em Economia.

\section{Definição e modelagem do problema}

\subsection{Caracterização do problema}

Considera-se um mercado formado por um conjunto $P=\{1, \ldots, m\}$ de regiões produtoras e um conjunto $M=\{1, \ldots, n\}$ de mercados consumidores, espacialmente distribuídos, onde a quantidade de produto ofertada por cada região sofre variações sazonais.

Nesse problema, sejam: $q_{i}^{t}$ a quantidade produzida pela região produtora $i$ no período $t, \mathrm{~d}_{\mathrm{j}}^{\mathrm{t}} \mathrm{a}$ quantidade consumida pelo mercado consumidor $j$ no período $t$ e $x_{i j}^{\mathrm{t}}$ a quantidade transportada (fluxo) da região produtora $i$ para o mercado consumidor $j$ no período $t$. Sejam $\mathrm{S}^{-1}{ }_{i t}\left(\mathrm{q}_{\mathrm{i}}^{\mathrm{t}}\right), \mathrm{D}^{-1}{ }_{\mathrm{jt}}\left(\mathrm{d}_{\mathrm{j}}^{\mathrm{t}}\right)$ e $\mathrm{C}_{\mathrm{ij}}^{\mathrm{t}}\left(\mathrm{x}_{\mathrm{ij}}^{\mathrm{t}}\right)$ funções continuamente diferenciáveis, representando, respectivamente, a curva inversa da oferta (ou custo marginal de produção) do mercado produtor $i$ no período $t$; a curva inversa de demanda (ou preço ao consumidor) do mercado consumidor $j$ no período $t$; e o custo marginal de transporte entre o produtor $i$ e o consumidor $j$ no período $t$.

Para esse problema, duas variantes são apresentadas. Na primeira delas considera-se o fato de não existir estoque regulador. Portanto a produção deverá ser consumida no mesmo período em que é ofertada. No caso seguinte considera-se a existência de um estoque regulador operado por um agente público, que armazena os excessos de oferta de um período para serem comercializados e consumidos no período seguinte, no qual a oferta é escassa. Dessa forma contribui-se para diminuir a variação observada nos preços do mercado. Nessa operação de armazenamento, os custos são repassados à sociedade sem visar lucro. 


\subsection{Formulação matemática para o caso sem estoque regulador}

Considera-se que cada região produtora pode comercializar sua produção em todos os mercados consumidores, conforme mostra a Figura 1.

Os preços e quantidades nesses mercados são definidos por um modelo de equilíbrio perfeito (Harker, 1986), onde a seguinte condição deve ser satisfeita:

$$
\forall i, j \quad S_{i t}^{-1}\left(q_{i}^{t}\right)+C_{i j}^{t}\left(x_{i j}^{t}\right) \begin{cases}=D_{j t}^{-1}\left(d_{j}^{t}\right) & \text { se } x_{i j}^{t}>0 \\ \geq D_{j t}^{-1}\left(d_{j}^{t}\right) & \text { se } x_{i j}^{t}=0\end{cases}
$$

Nesse caso consideram-se dois períodos isolados, denotados por $t \in\{1,2\}$, nos quais toda oferta disponível deve ser consumida no período em que é produzida. Assim, pode-se formular o problema de modo independente para cada período, como segue:

Maximizar

$$
f_{t}(d, q, x)=\sum_{j=1}^{n} \int_{0}^{d_{j}^{\prime}} D_{j t}^{-1}(w) d w-\sum_{i=1}^{m} \int_{0}^{q_{t}^{\prime}} S_{i t}^{-1}(w) d w-\sum_{i=1}^{m} \sum_{j=1}^{n} \int_{0}^{x_{j}^{\prime}} C_{i j}^{t}(w) d w
$$

Sujeito a:

$\sum_{j=1}^{n} x_{i j}^{t}=q_{i}^{t} \quad \forall i=1, \ldots, m$

$\sum_{i=1}^{m} x_{i j}^{t}=d_{j}^{t} \quad \forall j=1, \ldots, n$

$x_{i j}^{t} \geq 0 \quad \forall i, j$

No modelo acima, adaptado de Takayama \& Judge (1971), a expressão (2) refere-se à função objetivo, na qual é maximizado o excedente da sociedade no período $t$. As Equações 3 e 4 definem,

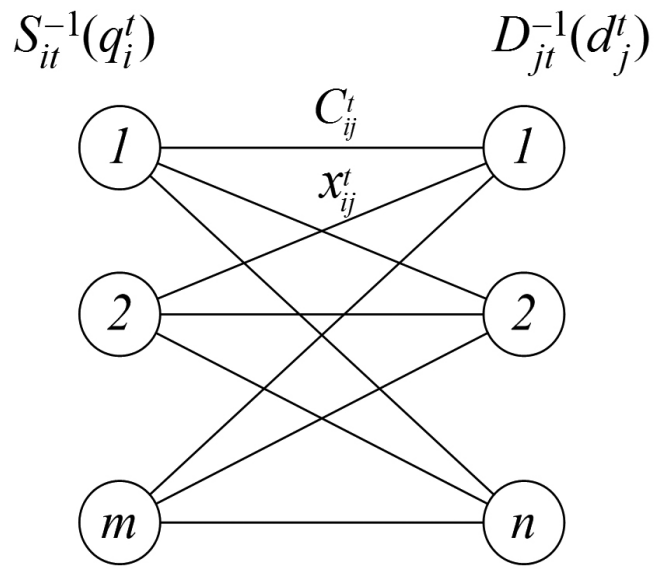

Figura 1. Estrutura espacial do mercado. Fonte: elaborado pelos autores. respectivamente, as quantidades produzidas pela região produtora $i$ no período $t$ e as quantidades consumidas no mercado $j$ no período $t$, em função das quantidades transportadas entre as regiões produtoras e os mercados consumidores nesse mesmo período. Finalmente, a expressão (5) refere-se à condição de não negatividade dos fluxos entre regiões produtoras e mercados consumidores. Aplicando KKT ao modelo acima, obtém-se que, na otimalidade, a condição (1) é satisfeita, isto é, a solução de máximo excedente da sociedade é equivalente à condição de equilíbrio em mercados perfeitamente concorrenciais.

Esse modelo pode ser resolvido, de modo independente, para cada período $t$, como um problema de otimização não linear restrito, usando algum método de direções viáveis. Para resolução desse problema, propõe-se o uso do algoritmo de projeção apresentado na seção 4.

\subsection{Formulação matemática para o caso com estoque regulador}

0 estoque administrado pelo governo tem o objetivo de regular a oferta ao longo do tempo. Essa intervenção do governo faz com que, no período de excesso de produção, o excedente seja armazenado, reduzindo a oferta para o mercado e fazendo com que os preços praticados se elevem. Por outro lado, o estoque armazenado é utilizado no período de escassez para aumentar a oferta no mercado, reduzindo os preços. Em outras palavras, o preço no mercado tende a equilibrar-se entre os períodos de sazonalidade.

0 estoque, no período $t$, comporta-se como um consumidor adicional, para, no período seguinte, ser tratado como oferta. Assim, não se pode mais tratar cada período de modo isolado, pois eles são acoplados através do estoque, conforme indicado no diagrama da Figura 2, para um horizonte de planejamento cíclico composto por dois períodos.

Considerando que não há interesse do governo em auferir lucro nessa operação de armazenagem, mas tão somente cobrir os custos marginais de operação, o mercado continua operando numa condição de competição perfeita. Então, além da condição (1), é necessário satisfazer a seguinte condição:

$S_{i t}^{-1}\left(q_{i}^{t}\right)+B_{i}^{t}\left(b_{i}^{t}\right)+Q^{t}\left(e^{t}\right)+R_{j}^{t+1}\left(r_{j}^{t+1}\right) \begin{cases}=D_{j, t+1}^{-1}\left(d_{j}^{t+1}\right) & \text { se } b_{i}^{t}>0, e^{t}>0 \text { e } r_{j}^{t+1}>0 \\ \geq D_{j, t+1}^{-1}\left(d_{j}^{t+1}\right) & \text { em caso contrário }\end{cases}$

onde:

$\mathrm{e}^{\mathrm{t}}=$ quantidade estocada no fim do período $t$;

$\mathrm{r}_{\mathrm{j}}^{\mathrm{t}}=$ quantidade enviada do estoque para o consumidor $\mathrm{j}$ no período $t$;

$b_{i}^{t}=$ quantidade enviada do produtor i para 0 estoque no período $t$. 


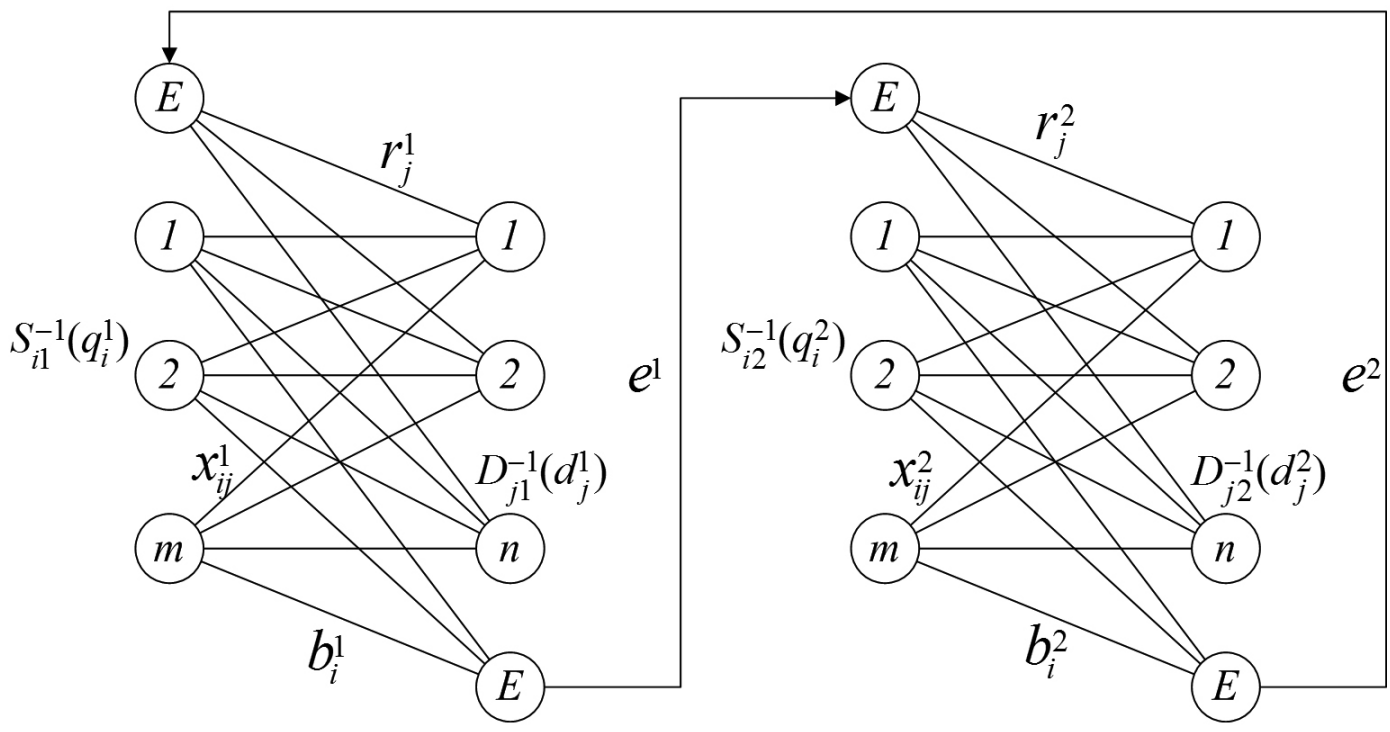

Figura 2. Estrutura espacial do mercado com estoques reguladores em dois períodos. Fonte: elaborado pelos autores.

Na expressão (6), as funções $Q^{t}\left(e^{t}\right), R_{j}^{t}\left(r_{j}^{t}\right)$ e $\mathrm{B}_{\mathrm{i}}^{\mathrm{t}}\left(\mathrm{b}_{\mathrm{i}}^{\mathrm{t}}\right)$ são continuamente diferenciáveis e definem para o período $t$, respectivamente, o custo marginal de estocagem, o custo marginal de transporte do estoque para os consumidores e o custo marginal de transporte dos produtores para o estoque. Os demais parâmetros e variáveis utilizados seguem definições apresentadas na caracterização do problema. Para obtenção da solução de equilíbrio é proposto o seguinte modelo:

Maximizar

$$
\begin{aligned}
& f(d, q, x, r, b, e)=\sum_{t=1}^{2}\left(\sum_{j=1}^{n} \int_{0}^{d_{j}^{t}} D_{j t}^{-1}(w) d w-\sum_{i=1}^{m} \int_{0}^{q_{t}^{t}} S_{i t}^{-1}(w) d w-\sum_{i=1}^{m} \sum_{j=1}^{n} \int_{0}^{x_{i j}^{t}} C_{i j}^{t}(w) d w\right. \\
& \left.-\sum_{j=1}^{n} \int_{0}^{r_{j}^{t}} R_{j}^{t}(w) d w-\sum_{i=1}^{m} \int_{0}^{b_{t}^{t}} B_{i}^{t}(w) d w-\int_{0}^{e^{t}} Q^{t}(w) d w\right)
\end{aligned}
$$

Sujeito a:

$\sum_{j=1}^{n} x_{i j}^{t}+b_{i}^{t}=q_{i}^{t}\left\{\begin{array}{l}\forall i=1, \cdots, m \\ \forall t=1,2\end{array}\right.$

$\sum_{i=1}^{m} x_{i j}^{t}+r_{j}^{t}=d_{j}^{t}\left\{\begin{array}{l}\forall j=1, \cdots, n \\ \forall t=1,2\end{array}\right.$

$\sum_{i=1}^{m} b_{i}^{t}=e^{t} \quad \forall t=1,2$

$\sum_{j=1}^{n} r_{j}^{1}=e^{2}$

$\sum_{j=1}^{n} r_{j}^{2}=e^{1}$ $x_{i j}^{t}, b_{i}^{t}, r_{j}^{t}, e^{t} \geq 0 \quad \forall i, j, t$

Nesse modelo, a função objetivo (7) continua sendo a maximização do excedente da sociedade; a restrição (8) assegura a conservação de fluxo referente ao produtor, enquanto que (9) é a restrição de conservação de fluxo associada ao mercado consumidor; a restrição (10) assegura a conservação de fluxo entre produção e armazenagem, enquanto que (11a e b) correspondem às restrições de conservação de fluxo entre armazenagem e consumo para cada um dos períodos. Finalmente, (12) são as restrições de não negatividade. Para esse modelo, as condições de equilíbrio ( 1 e 6 ) são satisfeitas, o que pode ser confirmado com a aplicação de KKT.

Da mesma forma que para o modelo da seção 3.2, para resolução do modelo (7-12) propõe-se o uso do algoritmo de projeção apresentado a seguir na seção 4.

\section{Algoritmo}

\subsection{Estrutura geral do algoritmo}

0 algoritmo utilizado para resolver os problemas formulados na seção 3 pode ser visto como uma particularização do método do gradiente projetado apresentado por Bertsekas (1999). Seja o problema de programação não linear na forma:

Maximizar $f(x)$

Sujeito a: $x \in K$ 
onde $f(x)$ é uma função continuamente diferenciável e $K \subseteq \mathbb{R}^{n}$ é um conjunto fechado e convexo. Então, os seguintes passos podem ser utilizados para a sua solução:

P1: Obtenha $\mathrm{x}^{0}$. Faça $\mathrm{k} \leftarrow 0$

P2: Calcule $x^{k+1} \leftarrow P_{K}\left(x^{k}+\beta \nabla f\left(x^{k}\right)\right)$

P3: Se $\left\|\mathrm{x}^{\mathrm{k}+1}-\mathrm{x}^{\mathrm{k}}\right\|>\varepsilon$, faça $\mathrm{k} \leftarrow \mathrm{k}+1$ e volte ao passo $\mathrm{P} 2$

\section{P4: Apresente $x^{k+1}$}

A adaptação realizada em relação ao método do gradiente projetado apresentado por Bertsekas (1999, seção 2.3) consiste na maximização da função objetivo e a particularização na escolha da estratégia constant stepsize para definição do passo. Como solução inicial, pode-se usar a solução nula, isto é, $\mathrm{x}^{0}=0$. No passo $\mathrm{P} 2, \mathrm{x} \leftarrow \mathrm{P}_{\mathrm{k}}(\mathrm{y})$ consiste na projeção ortogonal de $y \in \mathbb{R}^{n}$ no conjunto $K \subseteq \mathbb{R}^{n}$, conforme definição a seguir.

\section{Definição (projeção ortogonal)}

Seja K um conjunto fechado e convexo em $\mathbb{R}^{n}$. Então, para cada $y \in \mathbb{R}^{n}$ existe um único ponto $\mathrm{x} \in \mathrm{K}$, tal que:

$\|y-x\| \leq\|y-z\|, \quad \forall z \in K$

onde $x$ é conhecido como sendo a projeção ortogonal euclidiana de y sobre o conjunto K, isto é:

$x=P_{K}(y)=\arg \min _{z \in K}\|y-z\| \Upsilon$

No algoritmo proposto, dois aspectos precisam ser discutidos: a obtenção do gradiente da função objetivo e a realização da projeção sobre o conjunto viável. A seguir, esses aspectos são tratados para cada um dos modelos apresentados.

\subsection{Adaptação do algoritmo para o caso sem estoque}

0 modelo (2-5) pode ser reescrito como:

Maximizar $\hat{f}_{t}(x)=f_{1 t}(d(x))-f_{2 t}(q(x))-f_{3 t}(x)$

sujeito a: $\mathrm{x} \geq 0$

onde:

$$
\begin{aligned}
& f_{1 t}(d(x))=\sum_{j=1}^{n} \int_{0}^{d_{t}^{t}} D_{j t}^{-1}(w) d w \\
& f_{2 t}(q(x))=\sum_{i=1}^{m} \int_{0}^{q_{t}^{t}} S_{i t}^{-1}(w) d w
\end{aligned}
$$

$f_{3 t}(x)=\sum_{i=1}^{m} \sum_{j=1}^{n} \int_{0}^{x_{i j}^{t}} C_{i j}^{t}(w) d w$

e $d_{j}^{t}(x)$ e $q_{i}^{t}(x)$ são definidos pelas Equações (3) e (4), respectivamente. Essa representação é apropriada sob dois aspectos: permite calcular o gradiente da função objetivo e obter um esquema eficiente para realização do passo de projeção. Aplicando as propriedades usuais da derivação e a regra da cadeia, obtém-se $\nabla \hat{f}_{t}(x)$ como segue:

$\nabla \hat{f}_{t}(x)=\left[\begin{array}{c}D_{1 t}^{-1}\left(d_{1}^{t}\right)-S_{1 t}^{-1}\left(q_{1}^{t}\right)-C_{11}^{t}\left(x_{11}^{t}\right) \\ \vdots \\ D_{j t}^{-1}\left(d_{j}^{t}\right)-S_{i t}^{-1}\left(q_{i}^{t}\right)-C_{i j}^{t}\left(x_{i j}^{t}\right) \\ \vdots \\ D_{n t}^{-1}\left(d_{n}^{t}\right)-S_{m t}^{-1}\left(q_{m}^{t}\right)-C_{m n}^{t}\left(x_{m n}^{t}\right)\end{array}\right]$

A projeção $x^{k+1}=P_{K}\left(x^{k}+\beta \nabla \hat{f}_{t}\left(x^{k}\right)\right)$, dado o conjunto $K=\left\{x \in \mathbb{R}^{n} \mid x \geq 0\right\}$, pode ser realizada facilmente, considerando-se que apenas as restrições de não negatividade permanecem no modelo (16-17). Assim, tem-se, para o período $t$, na iteração $k+1$, a seguinte operação de projeção:

$x_{i j}^{t(k+1)}=\min \left\{0, x_{i j}^{t(k)}+\beta\left[D_{j t}^{-1}\left(d_{j}^{t}\right)-S_{i t}^{-1}\left(q_{i}^{t}\right)-C_{i j}^{t}\left(x_{i j}^{t}\right)\right]\right\}$

Finalmente, a convergência do método é assegurada para um $\beta$ suficientemente pequeno, dado que o gradiente satisfaz a condição de continuidade de Lipschitz.

\subsection{Adaptação do algoritmo para o caso com estoque regulador}

A função objetivo (7) pode ser reescrita como:

Maximizar

$f(d, q, x, r, b, e)=\sum_{t=1}^{2}\left[f_{1 t}(d)-f_{2 t}(q)-f_{3 t}(x)-f_{4 t}(r)-f_{5 t}(b)-f_{6 t}(e)\right]$

onde:

$f_{1 t}(d)=\sum_{j=1}^{n} \int_{0}^{d_{j}^{\prime}} D_{j t}^{-1}(w) d w$

$f_{2 t}(q)=\sum_{i=1}^{m} \int_{0}^{q_{i}^{t}} S_{i t}^{-1}(w) d w$

$f_{3 t}(x)=\sum_{i=1}^{m} \sum_{j=1}^{n} \int_{0}^{x_{i j}^{t}} C_{i j}^{t}(w) d w$

$f_{4 t}(r)=\sum_{j=1}^{n} \int_{0}^{r_{j}^{t}} R_{j}^{t}(w) d w$

$f_{5 t}(b)=\sum_{i=1}^{m} \int_{0}^{b_{t}^{t}} B_{i}^{t}(w) d w$ 


$$
f_{6 t}(e)=\int_{0}^{e^{t}} Q^{t}(w) d w
$$

Aplicando-se as propriedades usuais da derivação, obtém-se $\nabla f(d, q, x, b, r, e)$ como segue:

$$
\nabla f(d, q, x, b, r, e)=\left[\begin{array}{c}
\nabla f_{1 t}(d) \\
\nabla f_{2 t}(q) \\
\nabla f_{3 t}(x) \\
\nabla f_{4 t}(r) \\
\nabla f_{5 t}(b) \\
\nabla f_{6 t}(e)
\end{array}\right]=\left[\begin{array}{c}
D_{j t}^{-1}\left(d_{j}^{t}\right) \\
-S_{i t}^{-1}\left(q_{i}^{t}\right) \\
-C_{i j}^{t}\left(x_{i j}^{t}\right) \\
-R_{j}^{t}\left(r_{j}^{t}\right) \\
-B_{i}^{t}\left(b_{i}^{t}\right) \\
-Q^{t}\left(e^{t}\right)
\end{array}\right]
$$

A realização do passo P2 no algoritmo proposto em 4.1 consiste em projetar um ponto $y^{k}=x^{k}+\beta \nabla f\left(x^{k}\right) \in \mathbb{R}^{n}$ sobre um conjunto $\mathrm{K} \subseteq \mathbb{R}^{n}$ definido pelas restrições lineares (8-12). Genericamente, isso pode ser obtido através da resolução de um problema de programação quadrática, como segue:

$$
\operatorname{Minimizar} \sum_{j=1}^{n}\left(x_{j}^{k+1}-y_{j}^{k}\right)^{2}
$$

Sujeito a:

$\left(x_{1}^{k+1}, \ldots, x_{n}^{k+1}\right) \in K$

No problema (31-32), a função objetivo minimiza a distância euclidiana entre os pontos x e y, enquanto a restrição assegura que a projeção desejada encontra-se dentro do conjunto K. Assim, considerando-se que o conjunto $\mathrm{K}$ é definido por restrições lineares e que a função objetivo é convexa, pode-se obter a projeção pelo método proposto por Wolfe (1959) para resolução de problemas de programação quadrática. Note-se, entretanto, que para o caso particular de as funções de oferta, de demanda e de custos marginais de transporte e armazenamento serem lineares, o modelo (7-12) torna-se um problema de programação quadrática. Nesse caso, o método de projeção proposto pode ser substituído com vantagens pelo próprio método de Wolfe.

\section{Caso numérico}

Nesta seção discute-se um caso numérico particular, composto por um conjunto de três regiões produtoras, quatro mercados consumidores e dois períodos, cujos dados encontram-se no Apêndice. Sem perda de generalidade, nesse caso numérico ilustrativo as funções de oferta e de demanda são consideradas lineares, enquanto os custos de transporte são considerados constantes. As ofertas são distintas para cada um dos períodos, caracterizando-se a sazonalidade da produção, enquanto as demandas e os custos de transporte mantêm-se inalterados ao longo do tempo.

Aplicando-se o algoritmo de projeção da seção 4, com $\beta=1$, o problema sem estocagem (2-5) foi resolvido para ambos os períodos, com os dados disponíveis no Apêndice. Na Figura 3 é apresentada a evolução do valor da função objetivo em relação ao número de iterações realizadas, onde se observa a tendência de convergência exponencial.

Nas Figuras 4a e 4b observa-se a solução encontrada, obtida com uma precisão da ordem de $10^{-4}$, indicando os fluxos entre regiões produtoras e mercados consumidores e os preços praticados em cada região produtora e mercado consumidor.

Observa-se na figura que algumas regiões produtoras não transportam para certos mercados consumidores. Para esses casos, os custos marginais de produção, obtidos em função da produção de cada região, acrescidos dos respectivos custos marginais de transporte até as regiões consumidoras, excedem os preços praticados nos mercados consumidores, calculados em função das respectivas demandas. Esse fato inviabiliza a comercialização entre essas regiões. Para os demais casos, onde existe fluxo observa-se que o preço do mercado consumidor é igual à soma do custo marginal de produção com o respectivo custo de transporte. Em resumo, a condição (1) é satisfeita para todos os pares produtor/consumidor, necessária para a obtenção da solução ótima do modelo (2-5) e, consequentemente, do ponto de equilíbrio no mercado perfeitamente concorrencial. Os preços médios dos mercados consumidores e os fluxos totais de produção e consumo encontram-se destacados na Tabela 1.

A sazonalidade da oferta, nesse estudo de caso, faz os preços variarem consideravelmente. Observa-se que no primeiro semestre, quando a oferta é escassa, os preços praticados são elevados. Já no segundo semestre, quando a quantidade ofertada aos mercados

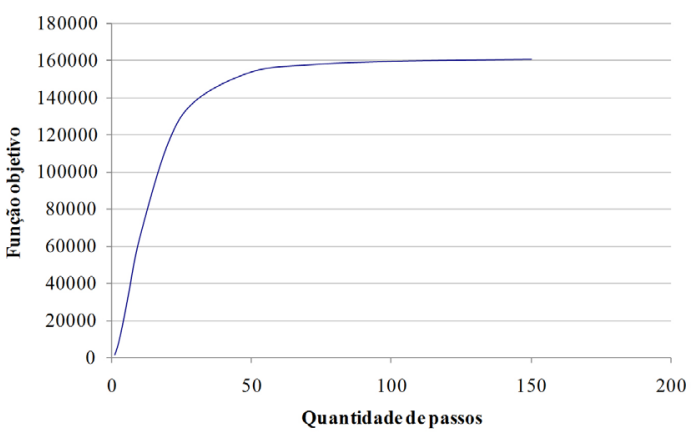

Figura 3. Convergência do algoritmo para o caso sem estocagem. Fonte: elaborado pelos autores. 

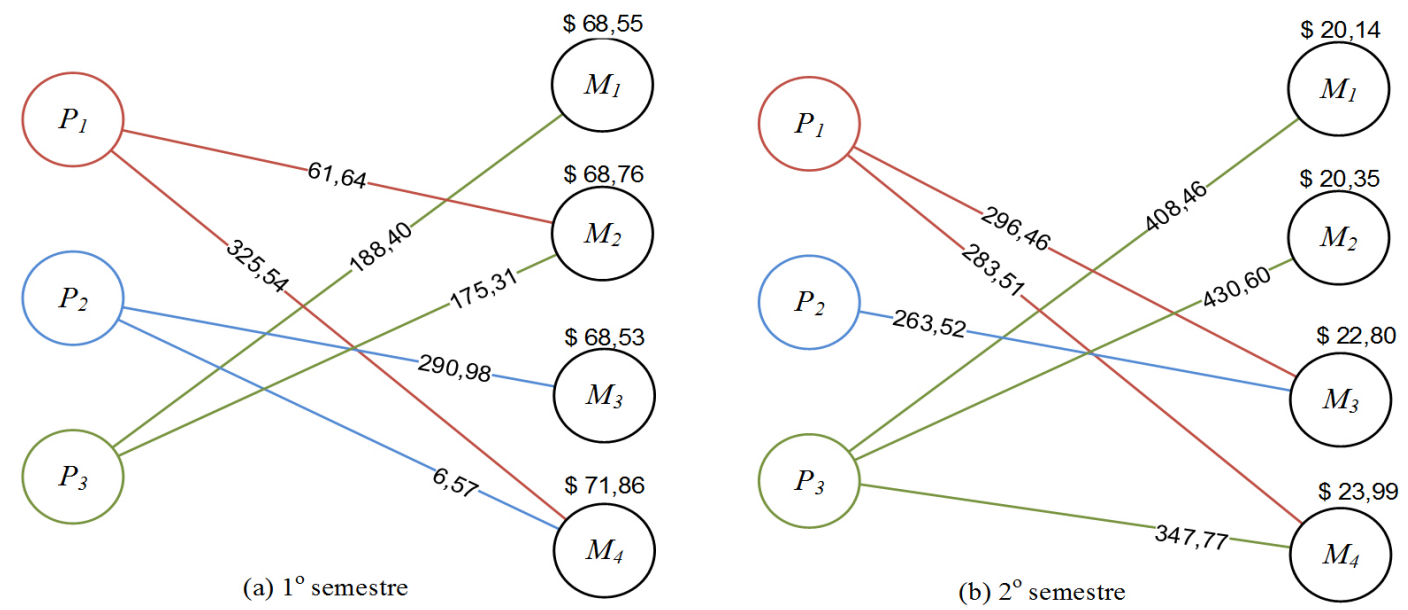

Figura 4. Fluxos entre produtores e consumidores e preços praticados nos mercados. Fonte: elaborado pelos autores.

Tabela 1. Problema sem estocagem.

\begin{tabular}{lcc}
\hline & $1^{\circ}$ semestre & $2^{\circ}$ semestre \\
\hline Preços médios & $\$ 69,43$ & $\$ 21,82$ \\
Produção total & $1.048,44$ & $2.030,33$ \\
Consumo total & $1.048,44$ & $2.030,33$ \\
\hline
\end{tabular}

Fonte: elaborada pelos autores.

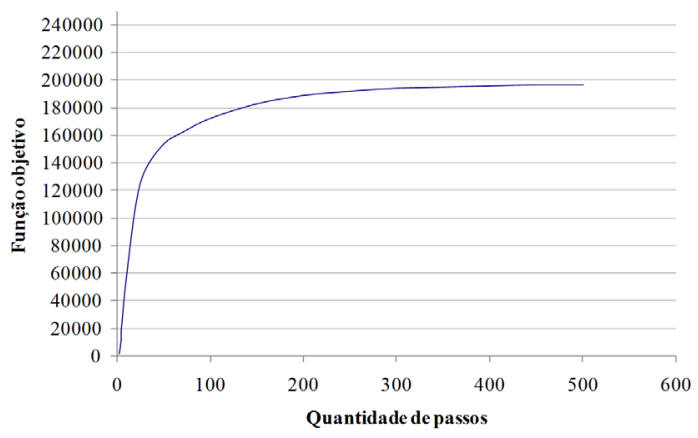

Figura 5. Convergência do algoritmo para o caso com estocagem. Fonte: elaborado pelos autores.

sofre um aumento de 93,6\%, tem-se uma redução dos preços médios em 68,6\%. Essa variação de preços representa riscos para os produtores e tende a inibir a realização de novos investimentos. Por outro lado, para o consumidor, períodos com preços elevados denotam a escassez do produto, impossibilitando o consumo por parte significativa da população.

No caso do problema com estoque regulador (7-12), considerando-se um custo de armazenagem constante (ver dados do Apêndice), a aplicação do algoritmo de projeção proposto na seção $4, \operatorname{com} \beta=1$, também proporcionou convergência exponencial, conforme mostra a Figura 5. Observa-se que, nesse caso, apesar de o problema ser de programação quadrática e o método indicado ser o proposto por
Wolfe (1959), utilizou-se o método de projeções, conforme descrito em 4.1 e 4.3, com o objetivo de avaliar o comportamento do método geral proposto.

Os resultados para esse caso, considerando-se uma precisão da ordem de $10^{-4}$, são apresentados na Figura 6.

Nessa solução verifica-se que as condições (1), (6) e (8-12) são todas satisfeitas, o que garante o equilíbrio do mercado perfeitamente competitivo, com estoque regulador. Observa-se, nesse caso, que a solução apresenta fluxo de armazenamento apenas do segundo para o primeiro período, ou seja, a armazenagem ocorre em períodos em que a oferta é abundante, para a venda ocorrer em um período de escassez. Note-se ainda, que a realização de armazenagem de produto do primeiro para o segundo período implicaria um prejuízo a ser bancado pelo governo, razão pela qual essa operação não é realizada. Por outro lado, os custos operacionais da armazenagem do segundo para o primeiro período se igualam à diferença entre o preço de compra e o preço de venda por parte do governo, fazendo com que não ocorra lucro nessa operação e nem prejuizos que tenham que ser repassados para a sociedade.

A Tabela 2 apresenta um resumo com os preços médios nos mercados consumidores, o total produzido e consumido em cada período, bem como a quantidade estocada. Nota-se, nesse caso, uma diminuição na variação dos preços médios praticados nos mercados consumidores, bem como no consumo observado em ambos os períodos, além do aumento da produção total.

Para o estoque administrado pelo governo tem-se a necessidade de manter-se uma capacidade para armazenamento de 1.551,46 unidades. Considerando a solução apresentada na Figura 6, conclui-se que o 


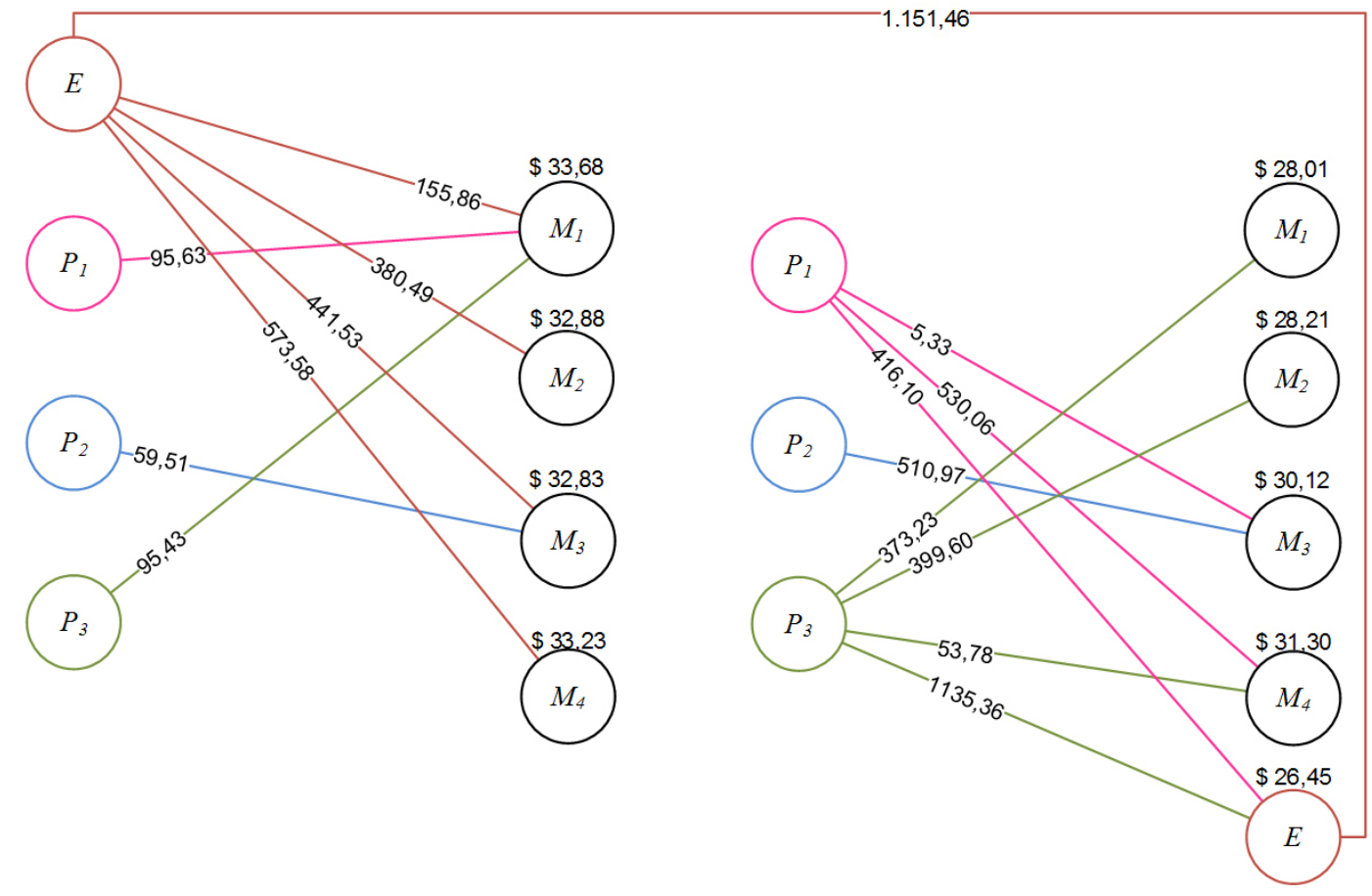

Figura 6. Fluxos e preços praticados nos mercados com estoque regulador. Fonte: elaborado pelos autores.

Tabela 2. Problema com estoque regulador do governo.

\begin{tabular}{lcc} 
& $1^{\circ}$ semestre & $2^{\circ}$ semestre \\
\hline Preços médios & $\$ 33,15$ & $\$ 29,41$ \\
Produção total & 250,57 & $3.424,40$ \\
Consumo total & $1.802,03$ & $1.872,96$ \\
Quantidade estocada & 0 & $1.551,46$ \\
\hline Fonte: elaborada pelos autores. &
\end{tabular}

preço de aquisição do produto por parte do governo é $\$ 26,45$ e que o preço de comercialização por parte dele é de $\$ 28,95$, que se refere ao valor de compra adicionado ao custo de estocagem.

Como medida de desempenho dos modelos apresentados neste trabalho avalia-se o valor do excedente da sociedade, que é dado pela soma do excedente do consumidor e do produtor, ilustrados na Figura 7.

0 excedente do produtor é dado pela diferença entre o valor que o produtor recebe pela venda de um bem (preço de mercado) e o valor mínimo que estaria disposto a aceitar (custo marginal) por ele. Pode-se obter esse excedente calculando-se a área destacada na Figura 7, isto é:

$$
E x_{\text {prod }}=q_{i}^{t} S_{i t}^{-1}\left(q_{i}^{t}\right)-\int_{0}^{q_{i}^{t}} S_{i t}^{-1}(w) d w
$$

Considerando-se a função de oferta dada por $S_{i t}^{-1}\left(q_{i}^{t}\right)=a_{i}+b_{i} q_{i}^{t}$, obtém-se:

$$
E x_{\text {prod }}=\frac{b_{i}\left(q_{i}^{t}\right)^{2}}{2}
$$

0 excedente do consumidor, por sua vez, é a diferença entre o valor máximo que o consumidor estaria disposto a pagar para consumir um bem e o valor que efetivamente paga (preço de mercado) por ele, e é calculado pela expressão:

$$
E x_{\text {cons }}=\int_{0}^{d_{j}^{t}} D_{j t}^{-1}(w) d w-d_{j}^{t} D_{j t}^{-1}\left(d_{j}^{t}\right)
$$

Sendo a demanda representada por uma função linear do tipo $D_{j t}^{-1}\left(d_{j}^{t}\right)=a_{j}+b_{j} d_{j}^{t}$, tem-se:

$E x_{\text {cons }}=-\frac{b_{j}\left(d_{j}^{t}\right)^{2}}{2}$

Aplicando as Equações (34) e (36) aos dados do caso numérico obtêm os resultados indicados na Tabela 3, onde o excedente da sociedade é dado pela soma dos excedentes do produtor e do consumidor.

Ainda que se questione o fato de os produtores terem visto o seu excedente total diminuído, em face da implantação da política de estoque regulador, há que se chamar atenção para o fato do ganho, por parte dos consumidores, ser amplamente favorável à sua implantação. Dessa forma, parte desse ganho poderia, eventualmente, ser usada para garantir alguma medida compensatória que devolvesse aos 

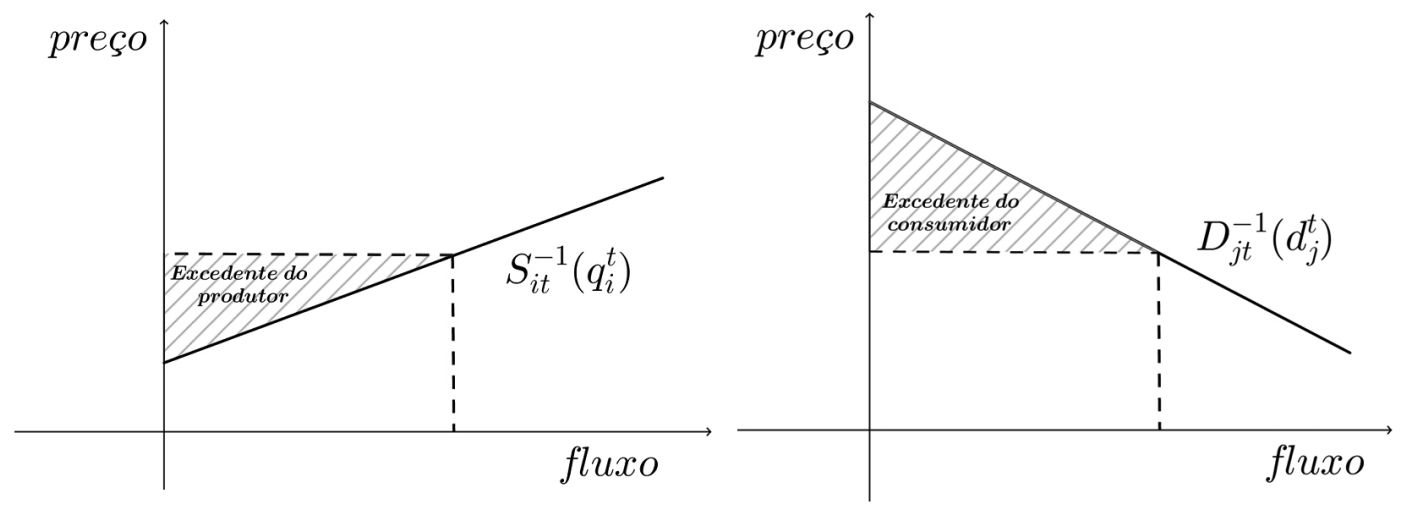

Figura 7. Excedentes do produtor e do consumidor. Fonte: elaborado pelos autores.

Tabela 3. Excedentes da sociedade.

\begin{tabular}{lcccc}
\hline \multirow{2}{*}{ Casos } & \multicolumn{4}{c}{ Excedentes } \\
\cline { 2 - 4 } & Produtor & Consumidor & Estoque & Sociedade \\
\hline Sem estocagem & $35.683,04$ & $127.009,22$ & - & $162.692,26$ \\
Com estocagem (governo) & $33.677,59$ & $164.359,06$ & 0 & $198.036,65$ \\
\hline
\end{tabular}

produtores parte das perdas acumuladas, na forma de incentivos indiretos como: linhas de crédito subsidiadas, renúncia fiscal, entre outros. Entretanto, um benefício evidente para o produtor que se pode apurar da implantação dessa política de estoque regulador é a estabilização dos preços no mercado, com a consequente redução dos riscos.

\section{Considerações finais}

Neste trabalho foi apresentado um modelo de estabilização de preços em mercados perfeitamente concorrenciais espacialmente distribuídos através de estoques reguladores, para uma commodity, considerando um horizonte de planejamento com dois períodos, caracterizados por safra e entressafra. Ao contrário do que se observa em outros trabalhos, neste não são estabelecidas políticas de preço mínimo para o produtor e/ou preço máximo para o consumidor. Ao invés disso, o modelo baseia-se na estratégia de maximizar o excedente da sociedade ao transferir estoques do período em que se observa excesso de oferta para o período com escassez. Essa estratégia permite uma melhor distribuição dos recursos envolvidos sem impor ao agente regulador ônus decorrente de sua operacionalização.

Esse modelo pode ser utilizado no caso de produtores e consumidores encontrarem-se espacialmente dispersos, o que representa melhor situações reais de mercado. Também é possível considerar esse modelo quando o armazenamento é realizado por múltiplos estoques, que tendem a agir de modo perfeitamente concorrencial, pois nesses casos as tarifas praticadas no armazenamento tendem ao custo marginal de estocagem.

Os resultados obtidos com casos numéricos mostram que o modelo proposto e a aplicação do algoritmo de projeção são eficazes na solução do problema.

Algumas extensões do modelo apresentado podem ser consideradas, tais como a inclusão de múltiplos períodos de sazonalidade.

\section{Referências}

Athanasiou, G., Karafyllis, 1., \& Kotsios, S. (2008). Price stabilization using buffer stocks. Journal of Economic Dynamics \& Control, 32, 1212-1235. http://dx.doi. org/10.1016/j.jedc.2007.05.004

Bertsekas, D. P. (1999). Nonlinear Programming. Belmont: Athena Scientific.

Brennan, D. (2003). Price dynamics in the Bangladesh rice market: implications for public intervention. Agricultural Economics, 29, 15-25. http://dx.doi. $\operatorname{org} / 10.1111 /$ j.1574-0862.2003.tb00144.x

Edwards, R., \& Hallwood, C. P. (1980). The Determination of Optimum Buffer Stock Intervention Rules. Quarterly Journal of Economics, 94, 151-166.

Harker, P. T. (1986). Alternative Models of Spatial Competition. Operational Research, 34(3), 410-425. http://dx.doi. org/10.1287/opre.34.3.410

Jha, S., \& Srinivasan, P. V. (2001). Food inventory policies under liberalized trade. International Journal of Production Economics, 71(1-3), 21-29. http://dx.doi. org/10.1016/S0925-5273(00)00104-3 
Nagurney, A. (1999). Network Economics - A Variational Inequality Approach (revised 2nd ed). Boston: Kluwer Academic Publishers.

Prasad, K. N., Banouei, A. A., \& Swaminathan, A. M. (1992). Weather-induced instability in agricultural produce with respect to buffer stocks in India and Iran: an integrated optimization and dynamic input-output model. International Journal of Production Economics, 26(1-3), 89-97. http:// dx.doi.org/10.1016/0925-5273(92)90050-H

Samuelson, P. A. (1952). Spatial Price Equilibrium and linear Programming. American Economic Review, 42, 283-303.
Sutopo, W., Nur Bahagia, S., Cakravastia, A., \& Arisamadhi, T. M. A. (2008). A Buffer stock Model to Stabilizing Price of Commodity under Limited Time of Supply and Continuous Consumption. Proceedings of The 9th Asia Pacific Industrial Engineering and Management Systems Conference (APIEMS), Bali.

Takayama, T., \& Judge, G. G. (1971). Spatial and Temporal Price and Allocation Models. North Holland: Amsterda.

Wolfe, P. (1959). The Simplex Method for Quadratic Programming. Econometrica, 27, 382-398.

\section{Abstract}

\section{Spatial price equilibrium with buffer stock}

This paper presents the problem of spatial equilibrium prices for seasonal products in an environment of perfect competition subject to buffer stock without bands. The problem is formulated as a nonlinear programming model. The solution is obtained using a projection algorithm, which is applied to a numerical illustrative case. The results are discussed and compared with the case in which there is no buffer stock.

\section{Keywords}

Network equilibrium. Nonlinear programming. Gradient projection methods.

\section{Apêndice - dados do problema numérico}

Seguem-se os dados numéricos para os casos com e sem estocagem.

Tabela 4. Curva de demanda dos mercados consumidores.

\begin{tabular}{cc}
\hline \multirow{2}{*}{ Consumidor } & Semestre 1 e 2 \\
\cline { 2 - 2 } & $D_{j t}^{-1}\left(d_{j}^{t}\right)=a_{j}+b_{j} \cdot d_{j}^{t}$ \\
\hline $\mathrm{M}_{1}$ & $D_{1 t}^{-1}\left(d_{1}^{t}\right)=110-0,22 \cdot d_{1}^{t}$ \\
$\mathrm{M}_{2}$ & $D_{2 t}^{-1}\left(d_{2}^{t}\right)=128-0,25 \cdot d_{2}^{t}$ \\
$\mathrm{M}_{3}$ & $D_{3 t}^{-1}\left(d_{3}^{t}\right)=118-0,17 \cdot d_{3}^{t}$ \\
$\mathrm{M}_{4}$ & $D_{4 t}^{-1}\left(d_{4}^{t}\right)=125-0,16 \cdot d_{4}^{t}$ \\
\hline
\end{tabular}

Fonte: elaborada pelos autores.

Tabela 5. Curva de oferta dos mercados produtores.

\begin{tabular}{ccc}
\hline \multirow{2}{*}{ Produtor } & Semestre 1 & Semestre 2 \\
\cline { 2 - 3 } & $S_{i 1}^{-1}\left(q_{i}^{1}\right)=a_{i}+b_{i} \cdot q_{i}^{1}$ & $S_{i 2}^{-1}\left(q_{i}^{2}\right)=a_{i}+b_{i} \cdot q_{i}^{2}$ \\
\hline $\mathrm{P}_{1}$ & $S_{11}^{-1}\left(q_{1}^{1}\right)=17+0,12 \cdot q_{1}^{1}$ & $S_{12}^{-1}\left(q_{1}^{2}\right)=4+0,02 \cdot q_{1}^{2}$ \\
$\mathrm{P}_{2}$ & $S_{21}^{-1}\left(q_{2}^{1}\right)=19+0,15 \cdot q_{2}^{1}$ & $S_{22}^{-1}\left(q_{2}^{2}\right)=10+0,03 \cdot q_{2}^{2}$ \\
$\mathrm{P}_{3}$ & $S_{31}^{-1}\left(q_{3}^{1}\right)=16+0,13 \cdot q_{3}^{1}$ & $S_{32}^{-1}\left(q_{3}^{2}\right)=3+0,01 \cdot q_{3}^{2}$ \\
\hline
\end{tabular}

Fonte: elaborada pelos autores.
Considera-se a armazenagem de um semestre para o outro e o custo de manutenção/operacional da commodity em estoque durante um semestre constante e igual a \$2,50 para os dois períodos de armazenagem. Não é considerado fluxo entre estoques. Os custos de transporte são constantes ao longo do ano, conforme a tabela 6.

Tabela 6. Custos de transporte em \$ por unidade transportada

\begin{tabular}{|c|c|c|}
\hline De & Para & Vetor custo de transporte \\
\hline Produtor & Consumidor & 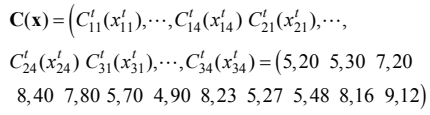 \\
\hline Produtor & Estoque & $\mathbf{B}(\mathbf{b})=\left(B_{1}^{t}\left(b_{1}^{t}\right) B_{2}^{t}\left(b_{2}^{t}\right) B_{3}^{t}\left(b_{3}^{t}\right)\right)=\left(\begin{array}{lll}3,60 & 3,20 & 3,70\end{array}\right)$ \\
\hline Estoque & Consumidor & 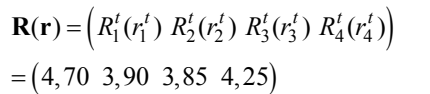 \\
\hline
\end{tabular}

